Check for updates

Cite this: Nanoscale Adv., 2019, 1, 1314

Received 14th December 2018 Accepted 9th February 2019

DOI: 10.1039/c8na00392k

rsc.li/nanoscale-advances

\section{Control of the compositions and morphologies of uranium oxide nanocrystals in the solution phase: multi-monomer growth and self-catalysis $\dagger$}

\author{
Qiang Yan, (D) ab Yiwu Mao, ${ }^{a}$ Xiaosong Zhou, ${ }^{a}$ Jianhua Liang, ${ }^{\text {a }}$ Shuming Peng*a \\ and Minyou $\mathrm{Ye}^{\star \mathrm{b}}$
}

\begin{abstract}
The presence of mixed products and impurities, which always confuse researchers, are common during synthesizing nanomaterials. Even though many studies have been conducted with an objective to control the synthesis of nanomaterials, very few studies have investigated a mechanism to control the composition of nanomaterials. Various products include $\mathrm{UO}_{3} \cdot \mathrm{H}_{2} \mathrm{O}, \mathrm{U}_{3} \mathrm{O}_{8}, \mathrm{UO}_{2}$, and $\mathrm{U}_{4} \mathrm{O}_{9}$ were produced by simply adjusting the $\mathrm{pH}$ with ammonia. The morphology of $\mathrm{UO}_{2}$ and $\mathrm{U}_{3} \mathrm{O}_{8}$ are tunable. In this study, we suggest two mechanisms that can be used to control the nanomaterial composition. Various experiments have been conducted to understand the mechanism that controls the composition of nanomaterials. We indicate that a multi-monomer growth model can be used to control the uranium oxide composition. We have developed a new oxidationreduction system using acetone, and this system is capable of controlling both the morphology and composition of uranium oxide micro/nanomaterials. Further, the presence of the self-catalysis mechanism can be used to regulate processes that control the monomer transformation. Thus, the results of this study can be applied to help in the construction of mixed-valence metal oxides.
\end{abstract}

Nanomaterials have attracted considerable attention due to their many unique and novel properties, such as optical, electronic, magnetic and catalytic properties. Nanomaterials have many potential innovative applications in various fields, as nanogenerators, ${ }^{1} \quad$ catalysts $^{2,3} \quad$ semiconductors, $^{,-6}$ photoluminescent materials $\mathrm{s}^{7,8}$ and biomedicines. ${ }^{\mathbf{9 , 1 0}}$ These properties are closely related to the shape and size of the materials.

A number of studies have attempted to control the synthesis of nanomaterials, of which most have focused on the size and shape of the nanomaterials. Numerous theories ${ }^{11-16}$ have been

${ }^{a}$ Institute of Nuclear Physics and Chemistry, China Academy of Engineering Physics, Mianyang, 621900, China. E-mail: pengshuming@caep.cn

${ }^{b}$ School of Physical Sciences, University of Science and Technology of China, Hefei, 230026, China. E-mail: yemy@ustc.edu.cn

$\dagger$ Electronic supplementary information (ESI) available: More details about experimental conditions, characterization and analysis are listed in ESI. See DOI: $10.1039 / \mathrm{c} 8 \mathrm{na00392k}$ proposed describing the control of the shapes or sizes of nanomaterials, such as the LaMer theory, agglomeration, aggregation, coalescence, orientation attachment (OA), the Kirkendall effect, self-assembly, and Ostwald ripening (OR). However, very few studies exist that discuss how to control nanomaterial composition. Thus, these mechanisms are proficient at describing the nucleation, growth process and shape changes of nanomaterials. However, they fail to explain the composition control and appearance of mixed products.

Impurities or mixtures are common in final products. For example, for $\mathrm{Fe}_{3} \mathrm{O}_{4} / \alpha-\mathrm{Fe}_{2} \mathrm{O}_{3}$ composites, ${ }^{17} \mathrm{U}_{3} \mathrm{O}_{8}$ appears in $\mathrm{UO}_{2}{ }^{18}$ and $\mathrm{Cu}$ in $\mathrm{Cu}_{2} \mathrm{O} .{ }^{19}$ The reason for the appearance of impurities or a mixture in the final products still puzzles researchers.

Uranium is best known, and feared, for its involvement in nuclear energy. Currently, uranium has been gaining an increased amount of attention due to its exclusive combination of properties. ${ }^{20}$ Uranium oxides also have a number of important properties, as well as their potential application as semiconductors, $^{21}$ and catalysts for short chain alkane destruction ${ }^{22}$ and volatile organic compound (VOCs) pollutants. ${ }^{2,23}$ On the other hand, uranium, which can form various oxides, is a multivalence state metal. Four of the uranium oxides are stoichiometric thermodynamically stable phases, i.e. $\mathrm{UO}_{3}, \mathrm{U}_{3} \mathrm{O}_{8}, \mathrm{U}_{4} \mathrm{O}_{9}$, and $\mathrm{UO}_{2} \cdot{ }^{24}$ The others are metastable stoichiometric phases, such as $\mathrm{U}_{2} \mathrm{O}_{5}$, which is only observable at elevated pressure, and $\mathrm{U}_{3} \mathrm{O}_{7}$, which appears only during $\mathrm{UO}_{2}$ oxidation at temperatures below $400{ }^{\circ} \mathrm{C} .{ }^{25}$ Therefore, uranium oxides are ideal materials to investigate the mechanisms that control composition.

As is well known, the composition of micro/nanomaterials changes with the alteration of reaction times, temperature, $\mathrm{pH}$, and chemical agent concentration during synthesis. Shi et al. ${ }^{26}$ produced $\mathrm{UO}_{2}$ nanospheres and $\mathrm{U}_{3} \mathrm{O}_{8}$ nanocuboids using a hydrothermal method. Wang et al. ${ }^{27}$ successfully synthesized ultrathin $\mathrm{UO}_{2}, \mathrm{U}_{3} \mathrm{O}_{7}$, and $\mathrm{U}_{3} \mathrm{O}_{8}$ nanomaterials using hydrothermal methods. However, the mechanism that plays an important role in forming the different valence state metal oxide products was unclear. 
In this study, we successfully controlled both the morphology and shape of uranium oxide nanomaterials in aqueous phases. Based on the results, we suggest two mechanisms that are crucial in controlling nanomaterial composition.

The uranium oxide nanocrystals were synthesized using a hydrothermal method. Uranium acetate hydrate (UAH) (100 $\mathrm{mg}$ ) was dissolved in a mixture of DI water $(5 \mathrm{~mL})$ and acetone $(10 \mathrm{~mL})$ in a capped glass bottle while being magnetically stirred. The ammonia (undiluted), ranging in volume from 25 $\mu \mathrm{L}$ to $1500 \mu \mathrm{L}$, was added to the solution to adjust the $\mathrm{pH}$ and stirred for 5 minutes. The entire mixture was then transferred to a $30 \mathrm{~mL}$ Teflon-lined stainless steel autoclave and sealed. The autoclave was maintained at $200{ }^{\circ} \mathrm{C}$ for 6 hours and cooled naturally to room temperature. The precipitates were centrifuged, and washed with ethanol and acetone. This procedure was repeated several times. Detailed experimental parameters are listed in the (ESI $\dagger$ ).

$\mathrm{X}$-ray powder diffraction (XRD) analyses indicate that the product compositions are different at various $\mathrm{pH}$ values (Fig. 1). The products include a mixture of $\mathrm{UO}_{3} \cdot \mathrm{H}_{2} \mathrm{O}$ and $\mathrm{U}_{3} \mathrm{O}_{8}(\mathrm{pH}=$ 4.76), pure $\mathrm{U}_{3} \mathrm{O}_{8}(\mathrm{pH}=7.83)$, a mixture of $\mathrm{U}_{3} \mathrm{O}_{8}$ and $\mathrm{UO}_{2}(\mathrm{pH}=$ 8.25), pure $\mathrm{UO}_{2}(\mathrm{pH}=9.81)$ and pure $\mathrm{U}_{4} \mathrm{O}_{9}(\mathrm{pH}=10.66)$.

The structures of $\mathrm{UO}_{2}$ and $\mathrm{U}_{4} \mathrm{O}_{9}$ are quite similar. The $\mathrm{UO}_{2}$ and $\mathrm{U}_{4} \mathrm{O}_{9}$ space groups (SG) are $F m \overline{3} m$ (SG no. 225) and $I \overline{4} 3 d$ (SG no. 220), respectively. The Bragg reflection of both $\mathrm{UO}_{2}$ and $\mathrm{U}_{4} \mathrm{O}_{9}$ products correspond to the standard face-centered cubic (FCC) structure. Distinguishing these two products in the XRD patterns is difficult (Fig. 1, the red and blue curves). However, the lattice parameter of $\mathrm{UO}_{2}(a=5.46 \AA)$ is slightly larger than that of $\mathrm{U}_{4} \mathrm{O}_{9}(a / 4=5.43 \AA)$. According to Bragg diffraction, the 2 theta degree of the corresponding peaks in $\mathrm{UO}_{2}$ was slightly smaller than that of $\mathrm{U}_{4} \mathrm{O}_{9}$ (Fig. S1a $\dagger$ ). On the other hand, the average $\mathrm{U}(\mathrm{v}+\mathrm{vI})_{4} \mathrm{O}_{9}$ valence state is higher than $\mathrm{U}(\mathrm{Iv}) \mathrm{O}_{2}$, which results in a higher binding energy for $\mathrm{U}_{4 \mathrm{f}}$ (Fig. S1b and $\mathrm{c} \dagger$ ). There are significant signals which allowed us to distinguish between $\mathrm{UO}_{2}$ and $\mathrm{U}_{4} \mathrm{O}_{9}$. Experiments without the addition of acetone yield pure $\mathrm{UO}_{3} \cdot \mathrm{H}_{2} \mathrm{O}$ (Table $\mathrm{S} 1 \dagger$ ). The product morphologies (Fig. S2 $\dagger$ ) and experimental conditions (Tables S1 and $\mathrm{S} 2.2 \dagger)$ are listed in the (ESI $\dagger)$.

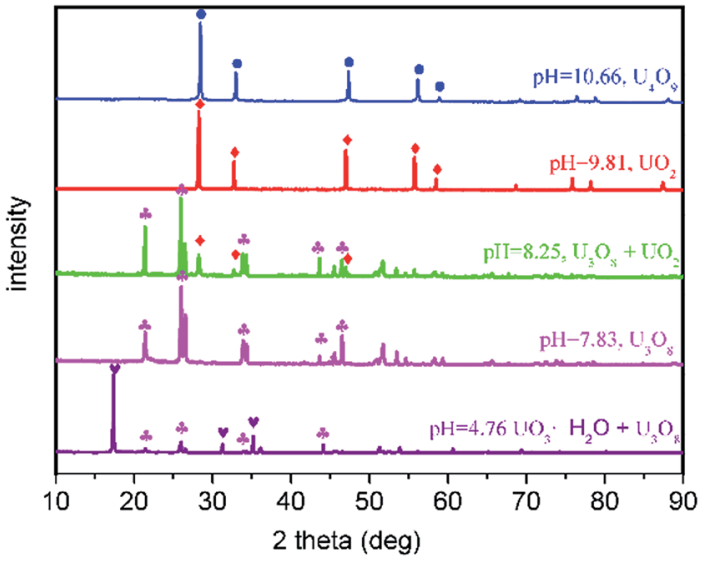

Fig. 1 XRD patterns of the products at various $\mathrm{pH}$ values (symbols: $=\mathrm{U}_{4} \mathrm{O}_{9}, \bullet=\mathrm{UO}_{2}, \quad \boldsymbol{\varphi}=\mathrm{U}_{3} \mathrm{O}_{8}$, and $\boldsymbol{\nabla}=\mathrm{UO}_{3} \cdot \mathrm{H}_{2} \mathrm{O}$.
The oxidation degree of the products decreased with increasing $\mathrm{pH}$ values. This implies that the system's reducing efficiency increased with increasing $\mathrm{pH}$ values. The presence of $\mathrm{U}_{4} \mathrm{O}_{9}$ at a higher $\mathrm{pH}$ is due to the rapid growth packaging in uranium at higher residual oxidation states. This mechanism is explained in the following discussion. The particle's volume decreased with increasing $\mathrm{pH}$ values (Fig. S1†), which implies that there is a decrease in the number of particles with the equivalent amount of raw materials.

To understand the mechanism that controls compositions, we performed a series of experiments (details are listed in $\mathrm{ESI} \dagger$ ). All of the experiments showed similar regularity as previously mentioned.

We have observed the presence of a mixed-valence uranium oxide, $\mathrm{U}_{3} \mathrm{O}_{8}$, when synthesizing $\mathrm{UO}_{2}$ nanocrystals with diethylene glycol (DEG). We suggested that there must be more than one type of monomer in the growth process of uranium oxides. ${ }^{\mathbf{1 8}}$ The mixed products in our experiments presented another kind of complexity. Fortunately, we obtained pure products for each phase and achieved morphological control (Fig. 2) by simply altering the experimental conditions (Tables S2.1 and S2.2†), which can help us to explore the control mechanisms.

LaMer $^{16}$ presented a theory to explain the formation of mono-dispersed hydrosols in 1950 (Fig. S6†). This is a classic mechanism to describe nanomaterial nucleation and growth processes in the liquid phase. However, the LaMer theory has limitations in explaining a mixed-valence metal oxide and the formation of mixed composition products.

In this study, we present a multi-monomer growth model to control the uranium oxide composition based on hundreds of experiments. We suggest that this model can be thought of as an extension of the LaMer theory and can be potentially extended to other multi-valence metal oxides.

In this model, each compound's valence (in solution) is considered to be an independent monomer that abides by the LaMer theory. As the concentration increases, the monomers

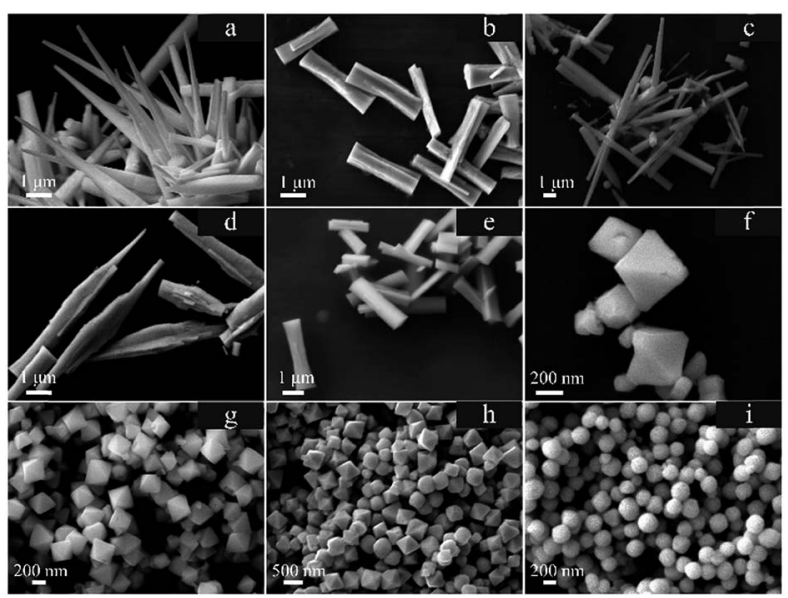

Fig. 2 SEM images of $\mathrm{U}_{3} \mathrm{O}_{8}(\mathrm{a}-\mathrm{e})$ and $\mathrm{UO}_{2}(\mathrm{f}-\mathrm{i})$ nanocrystals produced at various reaction conditions. Morphologies: (a) nail-like, (b) bonelike, (c) prism; (d) spear-like; (e) bone-like; (f) sunken octahedron; (g) octahedron; (h) smooth octahedron; and (i) spherical. The details of the experiments are listed in Tables S2.1 $\left(\mathrm{U}_{3} \mathrm{O}_{8}\right)$ and S2.2 $\left(\mathrm{UO}_{2}\right) \cdot \uparrow$ 
tend to aggregate and nucleate to reduce system energy when they overstep their minimum nucleation concentration. Impurities always appear when the reaction time is insufficient or due to temperature. We can obtain a pure product by prolonging the reaction time. ${ }^{18}$ However, sometimes prolonging the reaction time did result in pure product $\mathrm{B}$ being obtained and the products appeared as a mixture throughout the experiment, from beginning to end [Tables S3.1 and S3.2†].

We assume that two types of monomers, known as A and B, are in solution. The monomers include the formation of atoms, molecules or clusters. For example, we aimed to obtain the product B. Monomer A, which has a higher solubility, transferred to monomer B via a chemical reaction in solution. Due to its high solubility, monomer A remained below its minimum nucleation concentration (solid orange curve in Fig. 3). The concentration of monomer B increased with time, which led to its nucleation and growth (Fig. 3, blue solid curves). There are two potential pathways to produce mixture products or impurities. We hypothesize that the solubility of monomer A is higher than that of monomer B and also rapidly increases with increasing temperature. In the first pathway, the reaction ends and the temperature decreases rapidly before monomer $\mathrm{A}$ is completely depleted. The minimum nucleation concentration decreases with decreasing temperature. This is due to the fact that the critical solubility decreases when the temperature decreases. This leads to the concentration of residual monomer A (Fig. 3a, orange curve) exceeding the new minimum nucleation concentration at $T_{2}$ (Fig. 3a, dashed orange line). In the second pathway, the generation rate of monomer $\mathrm{A}$ is much faster than the depletion rate, which leads to a continuous increase in the concentration of monomer A (Fig. 3b, dashed orange line). After sufficiently long reaction times, monomer A can approach the minimum nucleation concentration. Both pathways promote the nucleation and growth of monomers A (Fig. 3a and b, orange curves), which further results in the production of mixed products or impurities.

We have verified these two hypotheses by experiments in this study [ESI, Section $2 \dagger$ ]. For the first situation, prolonging the reaction time contributes towards the yield of pure product $B$. However, this is useless for the second situation and we must alter the kinetic conditions.

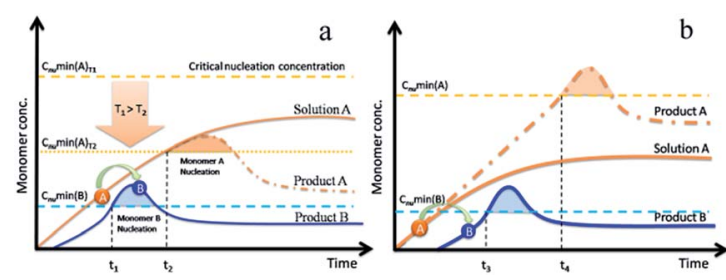

Fig. 3 Illustration of the bi-monomer growth mechanism for producing impurities or mixtures. (a) Ending the reaction by rapidly decreasing reaction temperature from $T_{1}$ to $T_{2}$. Minimum nucleation concentration (dashed orange lines) of monomer $A$ at $T_{2}$ is under the concentration of residual monomer $A$ (orange curves). (b) The reaction rate from $A$ to $B$ is too slow, which leads to an increase in the concentration of monomer $A$ above its minimum nucleation concentration with a sufficient reaction time $\left(t_{3}<t_{4}\right)$.
Kvashnina $^{28}$ and Gregory ${ }^{29}$ verified the uranium chemical state in mixed-valence uranium oxides by using high energy resolution fluorescence detection X-ray absorption near edge spectroscopy (HERFD-XANES) at the uranium M4 edge. Research results indicated $\mathrm{U}(\mathrm{vI})-\mathrm{U}(\mathrm{v})$ in $\mathrm{U}_{3} \mathrm{O}_{8}$ and $\mathrm{U}(\mathrm{v})-\mathrm{U}(\mathrm{vI})$ in $\mathrm{U}_{3} \mathrm{O}_{7}$ and $\mathrm{U}_{4} \mathrm{O}_{9}$. They did not observe a significant $\mathrm{U}(\mathrm{vI})$ contribution in $\mathrm{U}_{4} \mathrm{O}_{9}$ or a $\mathrm{U}(\mathrm{Iv})$ contribution in $\mathrm{U}_{3} \mathrm{O}_{8}$.

In this study, the final products include $\mathrm{UO}_{3} \cdot \mathrm{H}_{2} \mathrm{O}, \mathrm{U}_{3} \mathrm{O}_{8}$, $\mathrm{UO}_{2}$, and $\mathrm{U}_{4} \mathrm{O}_{9}$, simply synthesized from raw uranyl(Iv) acetate hydrate (UAH). Thus, the following equation represents the chemical reduction route:

$$
\text { Precursors } \rightarrow \mathrm{U}(\mathrm{vI}) \rightarrow \mathrm{U}(\mathrm{v}) \rightarrow \mathrm{U}(\mathrm{IV})
$$

The precursor is thought to be liquid uranyl $\left(\mathrm{UO}_{2}{ }^{2+}\right)$, which is characterized by high solubility, or the solid $\mathrm{U}_{2}\left(\mathrm{NH}_{3}\right) \mathrm{O}_{3} \mathrm{H}_{2} \mathrm{O}$ when significant amounts of ammonia were added. Monomers may exist in the form of atoms, monomers, hydrate compounds or clusters. The solubility of various uranium compounds is different and the solubility of $\mathrm{UO}_{3} \cdot x \mathrm{H}_{2} \mathrm{O}$ is much higher than $\mathrm{UO}_{2} \cdot x \mathrm{H}_{2} \mathrm{O} .^{30-32}$ Despite that, no other information on the solubility of $\mathrm{U}(\mathrm{v})$ exists. We assume that the critical solubility of $\mathrm{U}_{2} \mathrm{O}_{5}$ is between that of $\mathrm{UO}_{3}$ and $\mathrm{UO}_{2}$. This is insignificant to understand the mechanisms that induce multi-monomer growth.

The composition is usually controlled by thermodynamics. When the precursor decomposed into the U(vi) monomer, the redox reaction did not occur. There was only one type of monomer, occurring as $\mathrm{U}(\mathrm{vI})$, that resulted in the production of $\mathrm{UO}_{3} \cdot \mathrm{H}_{2} \mathrm{O}$ (Fig. 4a). We can use the LaMer theory to understand this situation. With an appropriate reducing condition, the monomer $\mathrm{U}(\mathrm{vI})$ was reduced to a $\mathrm{U}(\mathrm{v})$ monomer but the continuous reaction was limited by thermodynamics because there were two types of monomers, i.e. $\mathrm{U}(\mathrm{vI})$ and $\mathrm{U}(\mathrm{v})$, in the

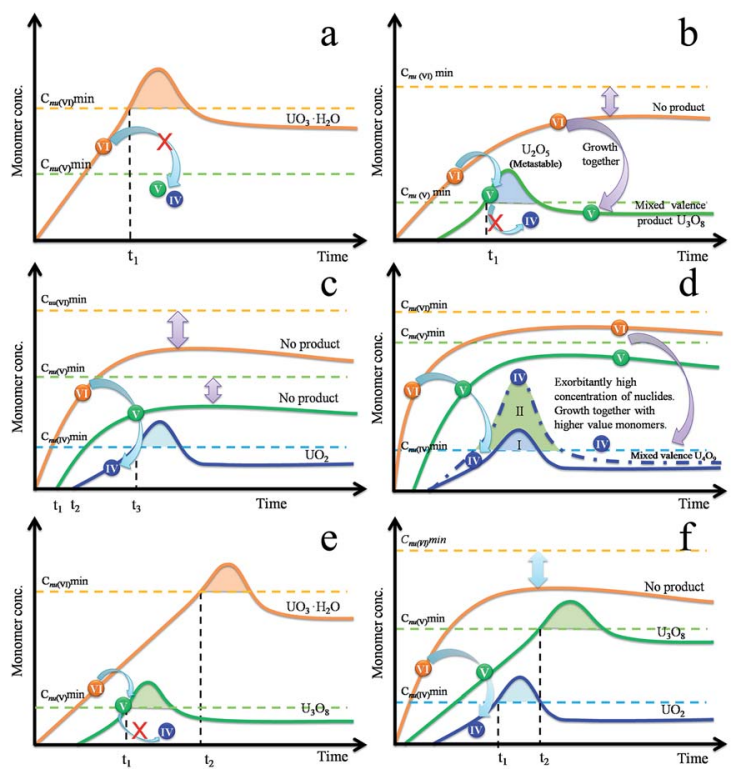

Fig. 4 Illustration of the multi-monomer growth mechanism that produces pure $(a-d)$ and mixed (e and f) uranium oxide nanocrystals. 
system. The $\mathrm{U}(\mathrm{v})$ monomer increased with time while the $\mathrm{U}(\mathrm{vI})$ monomer remained below its minimum nucleation concentration due to depletion during the redox reaction. Theoretically, this scenario may yield mono-valence $\mathrm{U}_{2} \mathrm{O}_{5}$ (orthorhombic) nanocrystals, while the final observed product was $\mathrm{U}_{3} \mathrm{O}_{8}$, which has an orthorhombic structure similar to that of $\mathrm{U}_{2} \mathrm{O}_{5} \cdot \mathrm{U}_{2} \mathrm{O}_{5}$ is a metastable phase and is only observed under pressure. The monomer $\mathrm{U}(\mathrm{vI})$ aggregated, nucleated and grew together with $\mathrm{U}(\mathrm{v})$, which resulted in the formation of a stable $\mathrm{U}_{3} \mathrm{O}_{8}$ phase (Fig. 4b).

$\mathrm{UO}_{2}$ was obtained when the reducing efficiency was enhanced and the U(Iv) monomer was produced. U(Iv) and U(v) also remained below their minimum nucleation concentration as in Fig. 4c. However, the formation of $\mathrm{U}_{4} \mathrm{O}_{9}$ was slightly different. The nucleation stage still depends on the concentration of $\mathrm{U}(\mathrm{IV})$ monomer as $\mathrm{UO}_{2}$. With a higher rate of reduction, the amount of nuclides increases, which results in the minimization of the particle volume with an equivalent amount of raw materials. The amount of nuclides increases significantly (Fig. 4d-II) with increasing supersaturation degree, which results in shortening of the diffusion distance of the monomer in solution. Due to the high concentration of particles, the residual $\mathrm{U}(\mathrm{v}) / \mathrm{U}(\mathrm{vI})$ monomers were covered into nanocrystals, then formed a stable phase $\mathrm{U}_{4} \mathrm{O}_{9}$. As a result of rapid growth, $\mathrm{U}_{4} \mathrm{O}_{9}$ formed as a sphere, not a polyhedron (Fig. S2f $\dagger$ ).

If the decomposition rate is much faster than the reduction rate, the $\mathrm{U}(\mathrm{vI})$ and $\mathrm{U}(\mathrm{v})$ monomer concentration continued to increase even after being depleted during the simultaneous redox reaction. As time progressed, each monomer approaches their critical nucleation concentration. As a result, this reduced a fresh round of nucleation and growth for the new phases (Fig. 4e and f). In this situation, prolonging the reaction time is useless when attempting to obtain pure target products.

Fortunately, we have verified all of the situations described above with experiments presented in this study (ESI, Section $2 \dagger)$. The morphologies can be tuned by adjusting the experimental conditions in a minor range after composition was under control; for example, by changing the amount of ammonia, concentration of UAH and the ratio of acetone to DI water (ESI, Section 1 and $2 \dagger$ ). On the one hand, the monomer generation rate, which might affect the amount of nuclides, may be affected by the acetone concentration, the initial uranyl amount and the $\mathrm{pH}$ value which influences the nucleation and growth kinetics. On the other hand, the ammonia might control the shape via surface adsorption. The shape of $\mathrm{UO}_{3} \cdot \mathrm{H}_{2} \mathrm{O}$ clearly changed with the addition of ammonia (Fig. S2 $\dagger$ ). In addition, the organic impurities, which also potentially affected the uranium oxide nanocrystals morphology, increased with $\mathrm{pH}$ and reaction time.

Controlling the nanocrystal shape during synthesis is both simple chemistry and complex physics. ${ }^{\mathbf{1 4}}$ As previously mentioned, controlling both the composition and morphology via a multi-monomer growth mechanism is quite complex. The question, therefore, is how to achieve this kind of control. In this study, we found a significant reaction system to attempt to answer this question. Due to the fact that acetone has no ability to act as a reducing agent, it is difficult to explain the synthesis of nanomaterials solely based on acetone as the reducing agent. The question, therefore, becomes how did acetone contribute to reduction at different $\mathrm{pH}$ values.

The gas chromatography mass spectrum (GC-MS) results showed that the products in solution phase include diacetone alcohol (DAA), mesityl oxide (MO), isomesityl oxide (IMO), 2,4dimethyl furan, phorone, trimethyl benzene (TMB) etc.

We summarized the main reaction pathways for acetone (Fig. S6 $\dagger$ ). The aldol addition reaction has been observed on various metal oxide surfaces including $\mathrm{U}_{3} \mathrm{O}_{8}, \mathrm{UO}_{2},{ }^{33} \mathrm{TiO}_{2},{ }^{34,35}$ $\mathrm{MgO},{ }^{36} \mathrm{ZrO}_{2}, \mathrm{La}_{2} \mathrm{O}_{3}, \mathrm{SrO}_{2}$, and $\mathrm{CaO} .{ }^{37}$ Only route 5 and 6 are redox reactions, ${ }^{38}$ which indicates that DAA and MO potentially acted as the reducing agent. Other experiments verified the reducing efficiency of MO but the morphologies of the solid products were irregular. The GC-MS results revealed that the oxidation product of MO is TMB (Table S6.2†). The composition of the products changed when the MO concentration was altered.

Extended experiments indicate that acetone could only be transferred to DAA at $200{ }^{\circ} \mathrm{C}$ without the addition of other agents (Table S6.1†). MO was detected after the addition of UAH. The MO fraction increased with the addition of ammonia. The amounts of organic by-products increase at higher $\mathrm{pH}$ values (Table $\mathrm{S} 7 \dagger$ ). Idiss et $a l^{.24}$ reported that aldolization of acetone occurs on the surface of uranium oxide and other metal oxides. This indicates that a self-catalysis process occurs at some point in this reaction system.

The whole process can be summarized as follows. In the first stage, the addition of sufficient ammonia generated the precursor $\left[\mathrm{U}_{2}\left(\mathrm{NH}_{3}\right) \mathrm{O}_{6} \cdot \mathrm{H}_{2} \mathrm{O}\right]$. In the second stage, the precursor decomposed into a $\mathrm{U}(\mathrm{vI})$ monomer at high temperatures. The concentration of $\mathrm{MO}$, which acted as an actual reducing agent, increased with time via acetone aldolization in basic conditions. This reaction rate was significantly affected by the $\mathrm{pH}$ value. The concentration of MO could have affected the reducing efficiency of the entire reaction system. The increased amount of ammonia promoted MO production, which acts as the actual reducing agent. Then, the $\mathrm{U}(\mathrm{vI})$ monomer was reduced to $\mathrm{U}(\mathrm{v})$ with a lower MO concentration and $\mathrm{U}(\mathrm{v})$ was reduced to $\mathrm{U}(\mathrm{Iv})$ with a relatively high $\mathrm{MO}$ concentration. The MO concentration, which was affected by $\mathrm{pH}$, acetone and uranyl concentration, could affect the redox rate. Thus, the complex physics for controlling both composition and morphology, was achieved easily with such a simple method.

In conclusion, we have developed a new oxidation-reduction reaction system with acetone, which is usually used as a purge agent or dissolvent. This reaction system is capable of controlling both the composition and morphology of uranium oxides micro/nanomaterials in the solution phase. We have presented two important mechanisms that control the composition of multi-value metal oxides. We developed an extended multimonomer growth model based on LaMer's theory, which was used to understand the formation of mixed-value metal oxides and mixture products. More importantly, the self-catalysis mechanism allows us to regulate the complex processes that control different monomer transformations. The results of this study have great potential to be used in the construction of 
other multi-value elemental compounds or mixed-valence metal oxides.

\section{Conflicts of interest}

There are no conflicts to declare.

\section{Acknowledgements}

The authors would like to acknowledge the financial support of Millions of Leading Engineering Talent from the first batch of the Ten Thousand Talent Program and the Science and Technology Foundation of China Academy of Engineering Physics (No. 2015B0302047).

\section{Notes and references}

1 Z. L. Wang, Adv. Mater., 2007, 19, 889-892.

2 G. J. Hutchings, C. S. Heneghan, I. D. Hudson and S. H. Taylor, Nature, 1996, 384, 341.

3 Z. T. Zhang, M. Konduru, S. Dai and S. H. Overbury, Chem. Commun., 2002, 2406-2407, DOI: 10.1039/b204987b.

4 X. Peng, Adv. Mater., 2003, 15, 459-463.

5 V. Biju, T. Itoh, A. Anas, A. Sujith and M. Ishikawa, Anal. Bioanal. Chem., 2008, 391, 2469-2495.

6 M. Zhu, J. Zhou, Z. Hu, H. Qin and X. Peng, ACS Photonics, 2018, 5, 4139-4146.

7 H. Qin, R. Meng, N. Wang and X. Peng, Adv. Mater., 2017, 29, 1606923.

8 J. Zhou, M. Zhu, R. Meng, H. Qin and X. Peng, J. Am. Chem. Soc., 2017, 139, 16556-16567.

9 Q. A. Pankhurst, N. T. K. Thanh, S. K. Jones and J. Dobson, J. Phys. D: Appl. Phys., 2009, 42, 224001.

10 L. Xu, Y. Liu, Z. Chen, W. Li, Y. Liu, L. Wang, Y. Liu, X. Wu, Y. Ji, Y. Zhao, L. Ma, Y. Shao and C. Chen, Nano Lett., 2012, 12, 2003-2012.

11 A. R. Tao, S. Habas and P. Yang, Small, 2008, 4, 310-325.

12 Z. Wu, S. Yang and W. Wu, Nanoscale, 2016, 8, 1237-1259.

13 Y. Xia, X. Xia and H.-C. Peng, J. Am. Chem. Soc., 2015, 137, 7947-7966.

14 Y. Xia, Y. Xiong, B. Lim and S. E. Skrabalak, Angew. Chem., Int. Ed., 2008, 48, 60-103.

15 C. Pu, H. Qin, Y. Gao, J. Zhou, P. Wang and X. Peng, J. Am. Chem. Soc., 2017, 139, 3302-3311.

16 V. K. LaMer and R. H. Dinegar, J. Am. Chem. Soc., 1950, 72, 4847-4854.
17 J. Ji, Y. Huang, J. Yin, X. Zhao, X. Cheng, S. He, X. Li, J. He and J. Liu, ACS Appl. Nano Mater., 2018, 1, 3935-3944.

18 Q. Yan, Y. Mao, X. Zhou, J. Liang, M. Ye and S. Peng, J. Nucl. Mater., 2018, 512, 417-422.

19 K. Chen and D. Xue, CrystEngComm, 2012, 14, 8068-8075.

20 M. J. Monreal and P. L. Diaconescu, Nat. Chem., 2010, 2, 424.

21 C. Young, J. Petrosky, J. M. Mann, E. M. Hunt, D. Turner and T. Kelly, Phys. Status Solidi RRL, 2016, 10, 687-690.

22 S. H. Taylor and S. R. O'Leary, Appl. Catal., B, 2000, 25, 137149.

23 S. H. Taylor, C. S. Heneghan, G. J. Hutchings and I. D. Hudson, Catal. Today, 2000, 59, 249-259.

24 H. Idriss, Surf. Sci. Rep., 2010, 65, 67-109.

25 S. Krivovichev, P. Burns and I. Tananaev, Structural chemistry of inorganic actinide compounds, Elsevier, 2006.

26 R. Zhao, L. Wang, Z.-J. Gu, L.-Y. Yuan, C.-L. Xiao, Y.-L. Zhao, Z.-F. Chai and W.-Q. Shi, CrystEngComm, 2014, 16, 26452651.

27 S. Hu, H. Li, H. Liu, P. He and X. Wang, Small, 2015, 11, 2624-2630.

28 K. O. Kvashnina, S. M. Butorin, P. Martin and P. Glatzel, Phys. Rev. Lett., 2013, 111, 253002.

29 G. Leinders, R. Bes, J. Pakarinen, K. Kvashnina and M. Verwerft, Inorg. Chem., 2017, 56, 6784-6787.

30 V. Neck and J. Kim, Radiochim. Acta, 2001, 89, 1-16.

31 T. Fanghänel and V. Neck, Pure Appl. Chem., 2002, 74, 18951907.

32 R. Jovani-Abril, M. Gibilaro, A. Janßen, R. Eloirdi, J. Somers, J. Spino and R. Malmbeck, J. Nucl. Mater., 2016, 477, 298304.

33 H. Madhavaram, P. Buchanan and H. Idriss, J. Vac. Sci. Technol., A, 1997, 15, 1685-1691.

34 W. Choi, J. Y. Ko, H. Park and J. S. Chung, Appl. Catal., B, 2001, 31, 209-220.

35 W. Xu and D. Raftery, J. Catal., 2001, 204, 110-117.

36 V. K. Díez, C. R. Apesteguía and J. I. Di Cosimo, J. Catal., 2006, 240, 235-244.

37 G. Zhang, H. Hattori and K. Tanabe, Appl. Catal., 1988, 36, 189-197.

38 C. O. Veloso, J. L. F. Monteiro and E. F. Sousa-Aguiar, in Studies in Surface Science and Catalysis, ed. J. Weitkamp, H. G. Karge, H. Pfeifer and W. Hölderich, Elsevier, 1994, vol. 84, pp. 1913-1920. 